\title{
Anti-CD98 Monoclonal Antibody IGN523
}

National Cancer Institute

\section{Source}

National Cancer Institute. Anti-CD98 Monoclonal Antibody IGN523. NCI Thesaurus. Code C113659.

A humanized, monoclonal antibody targeting the CD98 (gp125) antigen, with potential immunomodulatory and antineoplastic activities. Upon intravenous administration, IGN523 binds to CD98 expressed on the tumor cell surface and elicits both natural killer (NK)-cell mediated antibody-dependent cellular cytotoxicity (ADCC) and complementdependent cytotoxicity towards CD98-expressing tumor cells. In addition, IGN523 inhibits essential amino acid uptake by rapidly proliferating tumor cells. CD98, a type II transmembrane glycoprotein, is involved in both integrin signaling and amino acid transport processes; it is overexpressed in certain cancer cells and plays a key role in the proliferation, survival and metastasis of tumor cells. 